\title{
AS INTERAÇÕES ESPACIAIS NA CONFIGURAÇÃO E PRODUÇÃO DOS ARRANJOS FUNCIONAIS DAS CIDADES MÉDIAS
}

\section{THE SPATIAL INTERACTIONS IN CONFIGURATION AND PRODUCTION OF ARRANGEMENTS FUNCTIONAL ON MEDIUM-SIZED CITIES}

\author{
Marcos Jorge Godoy \\ Universidade Federal de Alfenas (UNIFAL), Alfenas, MG, Brasil, marcos.jgodoy@yahoo.com.br \\ Renan Fernando de Castro \\ Universidade Federal de Alfenas (UNIFAL), Alfenas, MG, Brasil, renan_fernando@ig.com.br \\ Flamarion Dutra Alves \\ Universidade Federal de Alfenas (UNIFAL), Alfenas, MG, Brasil, dutrasm@yahoo.com.br
}

\section{RESUMO}

Este artigo visa repensar a temática das interações espaciais sobre a perspectiva da reprodução socioespacial que envolvem as cidades médias. De tal maneira, fizemos uma releitura de autores como Richard Hartshorne, Edward Ullman e Roberto Lobato Corrêa sobre as definições das interações espaciais ao longo de cada momento histórico, apontando as contribuições de cada um desses autores para o assunto em questão. A materialização das formas e estruturas que configuram as cidades de médio porte é singular. Desse modo, não podemos generalizá-las, muito menos limitar nosso pensamento na conformidade de uma caracterização da dinâmica funcional dessas cidades como sendo reflexo das ações que decorrem nas metrópoles. Sendo assim, as cidades médias são classificadas por constituírem uma configuração que se diferencia das cidades grandes e metrópoles. Sua dinâmica evidencia uma interação entre campo e cidade, expressa pelas ruralidades que se entrelaçam sobre o urbano. Um entrelaçamento da divisão territorial do trabalho. As interações com outros centros urbanos estruturam e dão forma às redes geográficas regionais pautadas por cidades de pequeno e médio porte, e inserem essas cidades numa lógica orientada por uma economia globalizada. O que evidencia o caráter contraditório do processo de produção e reprodução socioespacial, visto através das espacialidades heterogêneas e singulares que se criam e recriam sobre a conformidade dessas interações espaciais às diferenciando da metrópole.

Palavras-chave: Interações Espaciais. Cidades Médias. Produção do Espaço.

\section{ABSTRACT}

This article aims to rethink the issue of spatial interactions on the perspective of socio-spatial reproduction involving medium-sized cities. So we did a reading of authors such as Richard Hartshorne, Edward Ullman and Roberto Corrêa Lobato on the definitions of spatial interactions along each historical moment, pointing out the contributions of each of these authors to the issue at hand. The materialization of forms and structures that shape the medium-sized cities is singular. Thus, we can not generalize them, much less limit our thinking in accordance with a characterization of the functional dynamics of these cities as reflecting the actions arising in the metropolis. Thus, the medium-sized cities are classified because they constitute a configuration that differs from the large cities and metropolises. Its dynamics shows an interaction between country and city, expressed by ruralities intertwine over urban. A tangle of territorial division of labor. Interactions with other urban centers structure and form regional networks geographical guided by small towns and mid-sized cities and insert these in a logic-driven globalized economy. What highlights the contradictory character of production and socio-spatial reproduction process, seen through the natural and heterogeneous spatiality that create and recreate on the conformity of these spatial interactions at differentiating the metropolis.

Keywords: Spatial Interactions. Medium-sized Cities. Production of Space.

Artigo recebido para publicação em dezembro de 2014

Artigo aceito para publicação em abril de 2015

\section{INTRODUÇÃO}


Este trabalho tem como objetivo repensar a temática das interações espaciais sobre a perspectiva da reprodução socioespacial que envolvem as cidades médias. Para tal, fez-se uma releitura sobre os temas em questão. Primeiramente, gostaríamos de ressaltar a relevância da análise dos temas "interações espaciais" e "cidades médias" na contribuição para com o avanço da ciência geográfica. Estes dois objetos geográficos vêm ganhando espaço nas discussões e estudos atuais, tanto no meio geográfico quanto na ciência econômica. Os aspectos que conferem a atual relevância sobre essas discussões estão ligados à conjuntura política e econômica que configura o planejamento socioespacial em detrimento da expansão do capital sobre o território, abrindo caminho para políticas de desenvolvimento local, regional e de integração que atuam sobre as formas, funções e estruturas das cidades médias.

Analisamos a cidade média como objeto particular, pautada sobre a articulação de redes geográficas que atuam em escalas menores, porém concentradas e de complexo arranjo organizacional. Dessa forma, podemos compreender mais sobre as interações espaciais que dinamizam as relações entre os espaços.

Buscamos através de uma releitura sobre o termo "interações espaciais", cunhado pelo geógrafo Edward Ullman, na década de 1950, evidenciar os principais momentos e emprego dessa temática dentro do meio geográfico. Para tanto, refletimos sobre a história do pensamento geográfico que norteou o pensamento anterior à formulação da temática e que serviu de base para tal concretização. Richard Hartshorne já havia explanado sobre a questão da "diferenciação de áreas" (HARTSHORNE, 1978), ideia que norteou os estudos de Ullman na forma de propor uma superação do tema, a fim de desenvolver um mecanismo de análise das interações e articulações entre áreas geográficas e que também permitisse a integração dessa ciência.

Por fim, far-se-á uma breve análise sobre essa temática explorada na geografia brasileira, sob a perspectiva e desenvolvimento teórico-prático de Roberto Lobato Corrêa. 
Ao que se sabe sobre a origem do termo aqui indagado, a primeira nota explanada sobre a temática das interações espaciais (do inglês Spatial Interactions) foi através do trabalho do geógrafo Edward Ullman na década de 1950. Ullman apresentou a temática das interações espaciais como forma de definição da interdependência entre dois ou mais lugares.

Ullman nesse momento faria um resgate do pensamento de Hartshorne (1978) no que confere a “diferenciação de áreas". Hartshorne (1978) criticava a forma pela qual era vista a geografia reduzida a uma concepção simplista de "diferenciação de áreas". Sendo explicada e banalizada pelo critério de sistematização dos elementos, principalmente os naturais, dando pouca ou quase nenhuma preocupação à análise da produção social e seus movimentos.

\footnotetext{
Com a introdução do homem na cena, esse aspecto dinâmico do caráter das áreas se torna muito mais importante, porque constitui um dos atributos particulares do homem o fato de que ele não apenas se desloca de um lugar para o outro, mas também põe as coisas em movimento. Por conseguinte, é sobretudo em seus aspectos humanos que as áreas diferem não apenas em sua morfologia, mas, igualmente, no que Ritter denominou sua fisiologia. Entretanto, para evitar qualquer analogia com os organismos vivos, seria preferível usar a expressão "relações funcionais", que envolve movimento de umas áreas para outras. (HARTSHORNE, 1978, p. $20)$.
}

Hartshorne apurou que a própria conotação da palavra diferenciação induzia o sentido de "diferenciar", desse modo, ficando impregnado sobre o julgamento do censo comum, o "fazer geografia" da época.

A maior parte das objeções levantadas contra o conceito identificado pela referida expressão foram dirigidos para aquilo que o crítico infere meramente através de sua interpretação das palavras que a constituem. Se as inferências do crítico o levarem a conclusões inaceitáveis, ele porá de lado não só a expressão mas também o conceito que ela denota. (HARTSHORNE, 1978, p. 13).

Portanto, para Hartshorne (1978) a forma com que os próprios geógrafos detinham a idéia sobre a expressão de diferenciação de áreas tinha de ser superada. Não mais se podia pensar a geografia como uma mera descrição das diferentes áreas e componentes do planeta, mas sim validar sua forma sobre a égide de uma ciência do estudo e análise de "variações diversas", que ocorrem entre o homem e o meio natural, e caberia ao geógrafo o olhar minucioso sobre o objeto analisado, pois a amplitude do próprio campo da ciência geográfica incita esse olhar.

Qualquer que seja o grau de integração que for estudado - desde o tópico até o regional - cabe ao investigador ter em mente, desde o início, se o seu propósito consiste primordialmente em 
desenvolver conclusões genéricas ou em examinar um caso individual. (HARTSHORNE, 1978, p. 173).

Hartshorne, assim, pregava o papel de liberdade do geógrafo. A diferenciação das áreas poderiam então estar sujeitas a inferências dedutivas do investigador. Para Hartshorne, esse avanço sobre o estudo da diferenciação das áreas possibilitaria para o geógrafo entender a relação entre os fenômenos que se relacionam em uma dada área, assim se poderia compreender o caráter total dessa área (HARTSHORNE, 1978), ou seja, inter-relacionando os aspectos e elementos, e, dessa forma, saindo do ostracismo de criar enciclopédias descritivas.

Ullman, em seus estudos, faz um resgate da concepção hartshorniana sobre a diferenciação de áreas, e propõe mudanças para melhor condizer com a aplicação do termo no estudo e análise dos fenômenos espaciais. Por meio de uma leitura geográfica do termo "complementaridade", do qual o definiu como sendo uma complementação funcional entre regiões separadas, ou seja, duas regiões articuladas através de funções complementares a cada uma, assim, fazendo-as dependentes através da necessidade diferencial entre os espaços. Nesse sentido, Edward Ullman usou o termo "complementaridade" para descrever uma das bases da interação espacial. (GREGORY et al., 2009).

Ullman classificou sua abordagem na forma de interações espaciais, pois notou que o próprio sentido da palavra "interações" correspondia a uma noção de "reciprocidade", denotada de "ação e movimento". Levando em conta, porém, que essa noção de reciprocidade era assimétrica, dando diferenciação da velocidade e intensidade dos movimentos de um lugar para outro.

A palavra "espaço", que complementa o termo de interação e dá caráter geográfico na amplitude do termo, ressalta o valor da ciência e pressupõe uma análise entre lugares que tem suas configurações a partir das interações que atuam sobre sua forma, ou seja, de modo genérico, caracteriza um processo dinâmico de fluxos de um local para o outro e a interdependência de regiões geográficas.

Segundo Catão et al. (2010), a ideia almejada por Ullman, era de fornecer à ciência geográfica um instrumento para entendimento e análise espacial. Ullman observou que através da temática das 
interações espaciais poder-se-ia então conceber unidade a esta ciência. Por outro lado, esse objetivo não foi alcançado, restando apenas uma fragmentação na utilização dessa temática entre as várias vertentes da geografia. (CATÃO et al., 2010).

No contexto do desenvolvimento desse pensamento, que desdobrou na fragmentação da temática das interações espaciais, temos uma incorporação dessa temática por uma geografia quantitativa, fortemente disseminada nas décadas de 1960 e 1970, baseada fortemente em números e estatísticas, e que buscava evidenciar as características expressas pelo espaço através da sistematização e quantificação de dados.

A exemplificar esse contexto no estudo da população, vimos que nesse momento suas características foram determinadas através de dados que manifestassem seu crescimento, movimento e desenvolvimento baseado em um agrupamento de dados agrupados que apenas reproduziam e informavam uma geografia de análise quantificadora e qualificadora.

No Brasil, Roberto Lobato Corrêa (1997) retoma a discussão das interações espaciais em seus estudos sobre as redes urbanas.

Corrêa (1997), ao discorrer sobre as interações espaciais, parte da concepção de que são definidas como sendo o processo que permeia o contato social, onde então se produzem formas, com funções orientadas pelas necessidades específicas a esse entrelaçamento social, ou seja, uma espacialidade configurada pelas funcionalidades que as relações impõem sobre os espaços.

As interações espaciais constituem um amplo e complexo conjunto de deslocamento de pessoas, mercadorias, capital e informação sobre o espaço geográfico. Podem apresentar maior ou menor intensidade, variar segundo a frequência de ocorrência e, conforme a distância e direção, caracterizar-se por diversos propósitos e se realizar através de diversos meios e velocidades. (CORRÊA, 1997. p. 279).

Portanto, para Roberto Lobato Corrêa (1997), a questão das interações espaciais pressupõe uma dinâmica de movimentos sobre um dado espaço, e que irão configurá-lo conforme a intensidade e complexidade que esse emaranhado de fluxos e contatos se dinamizam e interagem, ou seja, uma 
geografia de redes, integrada e sistêmica. Esse processo faz parte do movimento de "transformação social" (CORRÊA, 1997) e é através dele que também são produzidos e reproduzidos os espaços, evidenciando as necessidades históricas da sociedade em materializar e configurar seus espaços de vivência.

São nesses movimentos de articulações e vivências sociais, que se constituem as interações espaciais.

As formas criadas a partir desse conjunto de interações tendem a fomentar redes articuladas por funcionalidades e fluxos assimétricos. Tais funcionalidades podem ser vistas como base para a produção dos demais componentes que se materializarão sobre o tecido territorial, criando meios para que a reprodução socioespacial ocorra dinâmica e continuamente.

Pode-se inferir aqui, que o motor propulsor desse processo, que produz formas e move os agentes em direção a sua própria reprodução e articulação espacial, é basicamente a economia.

Desse modo, podemos incitar que a forma, ou melhor, os caminhos por onde esses fluxos, relações e/ou interações, melhor dito, decorrem, são representados através de uma rede urbana.

A assimetria das interações espaciais, aqui visualizada através dos fluxos da distribuição de bens, serviços, mercadorias, pessoas e informações, evidencia um emaranhado de caminhos, articulados por uma ordem hierárquica, por onde se conectam os centros urbanos e servem de base para a movimentação, circulação e troca dos bens, serviços, mercadorias, pessoas e informações de um local para o outro. Esse processo dinâmico e contínuo constitui uma teia que configura e articula o nó da rede.

A rede urbana é uma forma espacial, isto é, uma expressão fenomênica particular de processos sociais que se realizam em um amplo território envolvendo mediações diversas que se verificam nas cidades. (CORRÊEA, 2004, p. 37).

Podemos dizer, portanto, que a rede urbana é uma representação espacial dos caminhos que ligam e conectam os centros urbanos e seu grau de complexidade irá depender dos níveis de aperfeiçoamento 
das funcionalidades que as cidades ofertam. Segundo Corrêa (2004), "é através da forma que uma função se realiza, no caso, tratando-se de funções urbanas." (CORRÊEA, 2004, p. 37).

Assim, a melhor definição de rede urbana, e, que segundo Corrêa (2004) explicita sua dinâmica e interação espacial, é de que a rede urbana é "um conjunto funcionalmente articulado de centros urbanos e suas hinterlândias, envolvendo uma complexa diferenciação entre cidades" (CORREAA, 2004, p. 7).

Corrêa apresenta que as redes geográficas são, em dado momento de análise, "as formas com quais as interações espaciais se verificam" (CORRÊA, 1997, p. 295). Essa constatação pode ser vista na representação dos padrões de interações espaciais (Figura 1) e pela lógica das interações segundo suas variações espaço temporais apresentada por Corrêa (1997).

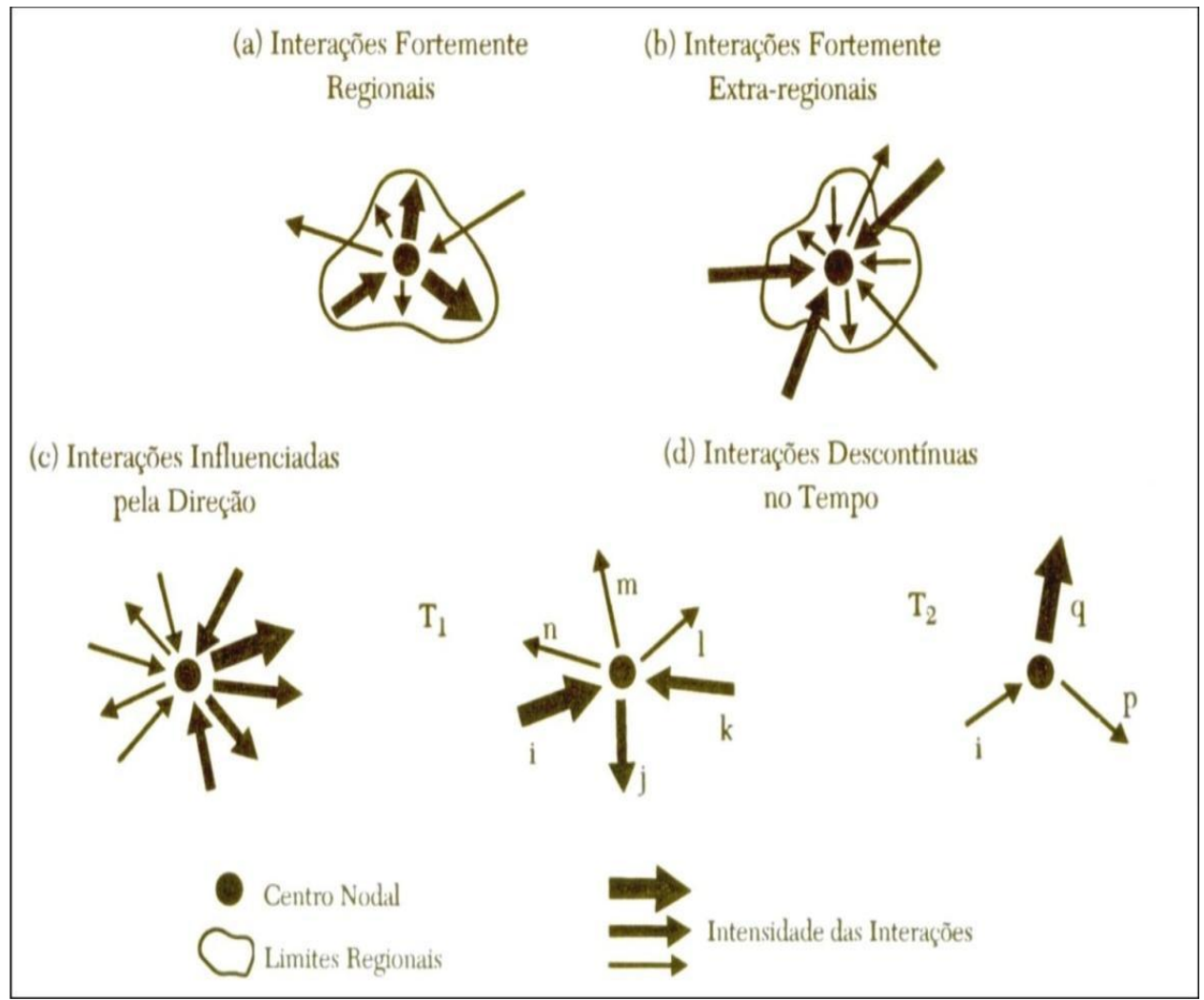

Figura 1. Padrões de interação espaciais e suas variações espaço temporais.

Fonte: Corrêa et al. (1997).

Segundo Corrêa (1997), as interações espaciais tendem a fluir em direção a um centro nodal, essa característica apontada por Corrêa evidencia a centralidade dos arranjos funcionais. Pois, segundo ele, 
os fluxos tendem a se orientar pela ordem expressa pela localidade que possui maior peso e influência sobre as outras (CORRÊEA, 1997). Essa teoria das localidades centrais de 1933, formulada por Christaller, é repensada por Corrêa, através da incorporação da teoria numa visão crítica, pautada sobre a análise dos processos de reprodução da sociedade capitalista, na contradição dos espaços em detrimento de uma lógica que "nega e transforma as coisas". (CORRÊAA, 2005).

Nesse sentido, é notório ressaltar que as interações espaciais são influenciadas e sofrem alterações, muito devido à localização das cidades dentro do arranjo e suas especializações funcionais, pois se um centro urbano mais afastado tem expressamente suas funções menos desenvolvidas, logo, sua articulação dentro da rede será menor, buscando estreitar relações com outros centros que o favoreçam.

\section{CIDADE MÉDIA: CENTRALIDADE, ARTICULAÇÃO E INTERAÇÕES ESPACIAIS}

Os estudos que levam em conta a análise que busca compreender a estrutura socioespacial das cidades médias vem ganhando espaço dentro da ciência geográfica e também da economia. A atual conjuntura nacional, pautada numa mundialização dos espaços, permitiu a penetração do capital e condução de políticas que privilegiassem o desenvolvimento social e econômico das cidades de médio e grande porte. Essas estratégias geridas em comum acordo entre capitalistas e Estado permitiram a ativação de fragmentos territoriais em escala regional.

Foi nesse contexto que se fortaleceram as redes urbanas formadas por cidades de pequeno e médio porte. As pequenas geralmente submissas a uma escala de poder exercida pelas cidades médias, onde se conectam a partir de uma lógica assimétrica, uma vez que a interação intra-rede privilegia um ou outro lugar, ressaltando a hierarquia urbana do arranjo, e submetendo as cidades menores e menos desenvolvidas a dependência econômica dos centros urbanos que tem suas funções ofertadas mais desenvolvidas.

Tal verificação acaba por fortalecer as conexões da rede. Uma vez que a dependência das cidades no arranjo funcional operado na rede limita a autonomia individual da gestão municipal, sobressaltando o 
poderio hierárquico das cidades, principalmente as que possuem uma maior e mais complexa dinâmica funcional.

Para compreendermos os processos que culminam sobre a configuração das cidades médias, devemos pensá-las como sendo um objeto particular, dotadas de uma divisão territorial do trabalho em escala de complexidade diferente da que encontramos nas metrópoles. Estas cidades médias evidenciam uma interação intraurbana promovida pela aproximação entre elementos do campo e cidade, produzindo espacialidades próprias, pautadas por um conjunto de relações sociais, econômicas e políticas que se desenrola sobre o espaço e ressalta uma interação de caráter dialético na produção de novos espaços, com novos usos, e formas que atendam as condições da reprodução do capital.

É necessário também pensar a cidade média como integrante de uma rede urbana local, que ora pode centralizar e polarizar uma região ou ser polarizada por outras, estabelecendo assim, uma relação de poder e formando uma rede de cidades interligadas, ou seja, uma hierarquia urbana entre as cidades que compõem a rede (SPOSITO, 2006). Desse modo, subordinando umas mais que outras, principalmente pelo nível de complexidade e desenvolvimento do emaranhado urbano e pela especialização das funcionalidades ofertadas pelas cidades.

Essas relações, analisadas como sendo processos que incumbem diretamente na estruturação e consolidação econômica dessas cidades de médio porte, influem sobre sua forma e estrutura, uma vez que produzem ou se especializam em novas funcionalidades que serão ofertadas e construirão novos caminhos na rede.

Algo que é notável nas ultimas décadas, em uma análise do contexto nacional, é de que vem ocorrendo nas cidades médias um aumento considerável da população e da economia, logo, do tecido urbano dessas cidades.

Ao observarmos um recorte de cidades médias do contexto sulmineiro, melhor caracterizado pela mesorregião Sul/Sudoeste de Minas Gerais, segundo classificação do IBGE (2010), podemos observar 
um crescente aumento populacional dessas cidades (QUADRO 1). Esse crescimento demográfico visto nas cidades médias do sul de Minas Gerais e que pode exemplificar a maturação econômica das cidades médias da região sudeste do Brasil (IBGE) pode ser explicado por três fatores principais e que se complementam:

a) A desconcentração da atividade industrial dos grandes centros em direção ao interior fomentada fortemente na década de 1990;

b) Políticas de desenvolvimento regional: que manteve sua preocupação na integração territorial e ativação econômica de fragmentações territoriais;

c) Disseminação do processo de informatização: acesso facilitado aos meios de comunicação. A internet também teve nesse momento papel fundamental para expansão populacional e econômica, promoção dos lugares e complemento fundamental da rede urbana, seja como produto ou como rota de transferência de dados.

Esses três fatores apresentados têm a globalização como elemento comum e propulsor de seus processos de expansão. Esta tornou possível a disseminação acelerada do capital e logo a incorporação de espaços em detrimento da reprodução do capital.

\begin{tabular}{ccccc}
\hline Municípios & $\mathbf{1 9 9 1}$ & $\mathbf{2 0 0 0}$ & $\mathbf{2 0 1 0}$ & $\begin{array}{c}\mathbf{2 0 1 3} \\
\text { (estimativa) }\end{array}$ \\
\hline Alfenas & 52.700 & 66.957 & 73.774 & 77.618 \\
Poços de Caldas & 110.123 & 135.627 & 152.435 & 161.025 \\
Pouso Alegre & 81.836 & 106.776 & 130.615 & 140.223 \\
Varginha & 88.022 & 108.998 & 123.081 & 130.139 \\
\hline
\end{tabular}

Tabela 1. Evolução do crescimento populacional nos respectivos municípios sulmineiros.

Fonte: http://sidra.ibge.gov.br/.

Para melhor se ter uma dimensão do crescimento demográfico das cidades médias sulmineiras (Tabela 1), observou-se também o crescimento da população do estado de Minas Gerais (Tabela 2) e da brasileira (Tabela 3) nos mesmos recortes de períodos:

\begin{tabular}{cccc}
\hline 1991 & $\mathbf{2 0 0 0}$ & $\mathbf{2 0 1 0}$ & $\begin{array}{c}\mathbf{2 0 1 3} \\
\text { (estimativa) }\end{array}$ \\
\hline 15.731 .961 & 17.866 .402 & 19.597 .330 & 20.593 .356 \\
\hline
\end{tabular}

Tabela 2. Evolução do crescimento populacional no Estado de Minas Gerais. 
Fonte: http://sidra.ibge.gov.br/.

\begin{tabular}{cccc}
\hline 1991 & $\mathbf{2 0 0 0}$ & $\mathbf{2 0 1 0}$ & $\begin{array}{c}\mathbf{2 0 1 3} \\
\text { (estimativa) }\end{array}$ \\
\hline 146.917 .459 & 169.799 .170 & 190.755 .799 & 201.032 .714 \\
\hline
\end{tabular}

Tabela 3. Evolução do crescimento populacional brasileiro.

Fonte: http://sidra.ibge.gov.br/.

Ao analisarmos os dados referentes ao crescimento populacional nas cidades médias sulmineiras e cruzarmos com os números dos PIBs (Produto Interno Bruto) por setores da economia de cada um desses municípios nas últimas duas décadas, pode-se notar a evolução significativa dessa mesorregião e sua progressão econômica.

Para tal constatação evidenciamos abaixo a dinâmica dos PIBs dos municípios de Alfenas, Poços de Caldas, Pouso Alegre e Varginha, frisando a participação dos setores da economia de cada um dos municípios analisados:

\begin{tabular}{ccc}
\hline Setores & $\mathbf{2 0 0 0}($ Mil R\$) & $\mathbf{2 0 1 0}($ Mil R\$) \\
\hline Agropecuária & 60.052 & 131.458 \\
Indústria & 92.758 & 198.096 \\
Serviços & 231.179 & 817.893 \\
Total & $\mathbf{4 3 4 . 8 3 8}$ & $\mathbf{1 . 2 8 2 . 8 3 0}$ \\
\hline
\end{tabular}

Tabela 4. Alfenas: Produto interno bruto no município referente aos anos de 2000 e 2010 (em Mil R\$).

Fonte: http://sidra.ibge.gov.br/.

\begin{tabular}{ccc}
\hline Setores & $\mathbf{2 0 0 0}($ Mil R $\$)$ & $\mathbf{2 0 1 0}($ Mil R $\$)$ \\
\hline Agropecuária & 23.440 & 48.945 \\
Indústria & 638.919 & 1.206 .640 \\
Serviços & 693.379 & 2.014 .504 \\
Total & $\mathbf{1 . 6 4 8 . 1 5 3}$ & $\mathbf{3 . 9 5 6 . 5 9 6}$ \\
\hline
\end{tabular}

Tabela 5. Poços de Caldas: Produto interno bruto do município referente aos anos de 2000 e 2010 (em Mil R\$).

Fonte: http://sidra.ibge.gov.br/.

\begin{tabular}{ccc}
\hline Setores & $\mathbf{2 0 0 0}($ Mil R\$) & $\mathbf{2 0 1 0}($ Mil R\$) \\
\hline Agropecuária & 27.185 & 58.349 \\
Indústria & 225.095 & 800.195 \\
\hline
\end{tabular}




\begin{tabular}{ccc}
\hline Serviços & 412.179 & 1.763 .612 \\
Total & $\mathbf{7 7 1 . 1 9 6}$ & $\mathbf{3 . 0 4 1 . 3 1 5}$ \\
\hline
\end{tabular}

Tabela 6. Pouso Alegre: Produto interno bruto do município referente aos anos de 2000 e 2010 (em Mil R\$). Fonte: http://sidra.ibge.gov.br/.

\begin{tabular}{ccc}
\hline Setores & $\mathbf{2 0 0 0}$ & $\mathbf{2 0 1 0}$ \\
\hline Agropecuária & 20.478 & 52.863 \\
Indústria & 217.408 & 720.349 \\
Serviços & 623.964 & 2.370 .608 \\
Total & $\mathbf{1 . 0 2 6 . 5 5 1}$ & $\mathbf{3 . 9 5 6 . 3 1 6}$ \\
\hline
\end{tabular}

Tabela 7. Varginha: Produto interno bruto no município referente aos anos de 2000 e 2010 (em Mil R\$).

Fonte: http://sidra.ibge.gov.br/.

O rápido crescimento populacional e econômico evidenciado nas cidades médias sulmineiras não é um fato isolado, tão pouco se restringe somente a essa região, mas pode também ser verificado em frações diversas do território nacional. Por outro lado, não podemos generalizar os aspectos, estruturas e processos que dão forma as cidades médias. Ao contrário do que comumente se pensa, a partir da ótica globalizacional, os espaços diferenciam-se, ressaltando as particularidades de cada lugar (SANTOS, 2006). Sua gênese pode passar pelo mesmo movimento, ou seja, pelos mesmos interesses que se fazem sobre a ativação econômica e apropriação dos lugares, mas são os fatores históricos e sociais que incumbem significativamente sobre a produção e reprodução espacial, caracterizando as singularidades dos espaços, deixando a marca histórica e social sobre suas formas.

\footnotetext{
A cada momento, cada lugar recebe determinados vetores e deixa de acolher muitos outros. É assim que se forma e mantém a sua individualidade. 0 movimento do espaço é resultante deste movimento dos lugares. Visto pela ótica do espaço como um todo, esse movimento dos lugares é discreto, heterogêneo e conjunto "desigual e combinado". Não é um movimento unidirecional. Pois os lugares assim constituídos passam a condicionar a própria divisão do trabalho, sendolhes, ao mesmo tempo, um resultado e uma condição, senão um fator. Mas é a divisão do trabalho que tem a precedência causal, na medida em que é ela portadora das forças de transformação, conduzidas por ações novas ou renovadas, e encaixadas em objetos recentes, que as tornam possíveis. (SANTOS, 2006. p. 87).
}

Como sabemos a globalização por si é contraditória. Os processos podem relativamente serem os mesmos, porém os espaços produzidos são de forma singular em cada localidade, em cada arranjo. Pois, conserva-se a heterogeneidade dos espaços, sua condição histórica e social se contrapõe sobre os 
processos incorporadores da globalização. E essa própria condição contraditória, possibilita a formação de espacialidades únicas.

Por outro lado, são notáveis nas cidades médias algumas similaridades que a tornam um objeto particular e que a diferencia da cidade grande e metrópole. É visível nas cidades médias do interior brasileiro o entrelaçamento de componentes do campo e cidade, dinamizando as relações sociais, e, portanto, as interações socioespaciais. Verifica-se, por exemplo, formas e manifestações culturais oriundas da vida do campo sendo incorporadas e transformadas pela vivência, cotidiano e dinamismo do urbano da cidade média.

Vê-se ainda, um acentuado desenvolvimento funcional das cidades médias, que se reflete numa oferta especializada de bens e serviços e que é verificada através da formação de uma rede urbana (CORRÊEA, 2004).

Esse apontamento é notável devido à identificação de dois movimentos que se complementam: uma força de atração; que tende a centralizar na cidade média mais desenvolvida o poder exercido através de uma hierarquia urbana que influi sobre a hinterlândia da cidade média, encarregada da função centralizadora dos aparatos funcionais mais bem desenvolvidos, e, concentradora dos fluxos de pessoas e de matérias primas que abastecem seus aparatos e estruturas funcionais.

O segundo movimento é reforçado pelo primeiro, sendo ele caracterizado pela escoação de mercadorias pela rede, podendo ser identificado pela movimentação e fluxos dados pela cidade central em direção a sua hinterlândia, quanto os fluxos entre as demais localidades que compõem a rede. Evidenciando, portanto, a complexa interação espacial intrarede, caracterizada pela densidade dos fluxos.

Uma característica observada em campo durante a análise das cidades médias sul mineiras, e, que vale ressalvar na forma de reforçar o objeto de estudo que é a cidade média e suas interações espaciais, é de que a população regional integra-se com as cidades médias centrais na forma de mão de obra e potencial consumidora das funcionalidades ofertadas por esses centros regionais mais desenvolvidos. 
Outro ponto notável é o modo como que se desdobra a interação entre campo e cidade. Este entrelaçamento de relações socioespaciais produz particularidades visíveis também na forma em que os dois circuitos da economia urbana, propostos por Milton Santos (2008), se configuram e apresentam espacialmente no recorte analisado.

Santos (2008) caracteriza os circuitos da economia urbana através do diferencial das atividades e seu grau de envolvimento tecnológico e organizacional. Enquanto as atividades do circuito superior estão ligadas ao grande capital; créditos burocráticos, como ações e especulações, as atividades do circuito inferior se reproduzem através de créditos muitas vezes convencionais, como o "dinheiro liquido" (SANTOS, 2008), que é necessário para a rotatividade e continuidade da atividade desempenhada, impossibilitando a acumulação de capital. Segundo Santos (2008): "O circuito superior utiliza uma tecnologia importada e de alto nível, uma tecnologia "capital intensivo", enquanto no circuito inferior a tecnologia é "trabalho intensivo" e frequentemente local ou localmente adaptada ou recriada." (SANTOS, 2008, p. 43).

Nota-se que as atividades ligadas ao circuito informal são produzidas conforme as necessidades que exprimem sobre a confluência da relação campo-cidade nas cidades médias sulmineiras. Do mesmo modo, são captadas e desenvolvidas atividades mais complexas ligadas ao grande capital, fortalecendo o circuito superior da economia urbana. Ou seja, é promovido um conjunto de relações dialéticas, que por um lado tem como objetivo reproduzir o grande capital através do circuito superior e por outro lado esse processo acaba resultando na (re)produção de atividades do circuito inferior (Santos, 2008).

A região sulmineira, por exemplo, é uma grande produtora de café e concentra nas cidades médias as indústrias processadoras dessa cultura. Desse modo é notável uma terceirização do que é produzido na terra, ou seja, uma imposição sobre os pequenos e médios agricultores que reforça uma interação de caráter de dependência desses agricultores com as indústrias cafeeiras locais, evidenciando que as cidades médias desse contexto se apropriam da renda fundiária da região a qual centralizam. 
As interações entre esses espaços propiciam formas de relações socioespaciais que se fundem e criam novas particularidades. É na aproximação entre o campo e cidade que se faz manifestar as ruralidades no intraurbano da cidade média, fortalecendo a presença e reprodução desses aspectos (CARNEIRO, 1998).

Carneiro (1998) aponta um olhar sobre a construção da ruralidade urbana, sendo essa, resistência pela aproximação entre esses dois espaços que se diferem, de modo que a ruralidade se transforma e se adapta a essa nova condição, ou seja, se transforma e fortalece.

Sampaio (2010) reforça a ideia da interação entre o campo e cidade através do desenvolvimento tecnológico e dos meios de locomoção que permitiram a maior circulação de pessoas entre as localidades, facilitando o acesso e promovendo as relações entre o urbano e rural e principalmente 0 estreitamento dessas relações sociais na reprodução das espacialidades das cidades médias.

\footnotetext{
Do ponto de vista do mercado consumidor, as cidades médias desempenham o papel dos polos para os quais os moradores de cidades menores e de áreas rurais estão dispostos a se deslocar em virtude que o tempo para esses deslocamentos tem diminuído, diante das melhorias dos transportes, inclusive, com o aumento de veículos próprios, bem como a frequência de viagens propiciadas pelo transporte coletivo. (SAMPAIO et al., 2010, p. 2).
}

Essas interações espaciais que evidenciam características do campo na cidade média, de certo modo, são produzidas pela forma que a cidade média se relaciona e articula dentro de uma rede urbana. Como as redes urbanas regionais, que tem a cidade média como centralizadora e polarizadora das atividades funcionais sobre sua hinterlândia, são compostas por cidades pequenas e médias, logo a aproximação e o contato com as cidades pequenas, acabam por influir aspectos rurais nesse meio de interação. Pois, sabe-se que as cidades pequenas do contexto sulmineiro, são geralmente ligadas a atividades rurais, ou seja, tem uma ou outra funcionalidade mais bem desenvolvida. Porém, suas funcionalidades de "sobrevivência", geralmente estão ligadas a manutenção de atividades relacionadas ao campo, como a agricultura e a pecuária, tendo um urbano pouco desenvolvido em nível de articulação com outros centros, por possuir uma singela complexidade de sua forma e estrutura funcional e uma oferta de serviços pouco especializada. 
Ao analisar a estrutura morfológica das cidades médias de Minas Gerais, Amorim Filho e Nelson de Sena Filho (2007) destacam também a interação entre periferia e o espaço rural:

\begin{abstract}
As unidades mal organizadas, denominadas localmente de vilas e que, mesmo que se diferenciem fisionomicamente das favelas das cidades maiores, são habitadas por populações com grandes dificuldades para se integrarem aos sistemas ou circuitos formais que estruturam a vida de relações da cidade. Por isso, vários dos habitantes dessas vilas acabam por integrar-se aos circuitos informais urbanos ou, então, em certos casos, mesmo continuando a habitar esses núcleos periféricos, voltam a buscar trabalho na área rural, de onde vários deles haviam saído. Assim, não causa surpresa o fato de algumas dessas unidades periféricas mal integradas apresentarem características fisionômicas que lembram, em muitos aspectos, os povoados rurais pobres que ainda subsistem em certas partes do Estado de Minas. (AMORIM FILHO SENA FILHO, 2007, p 69-70).
\end{abstract}

Essa descrição feita pelos autores a respeito das características da periferia da cidade média comprova a forte manifestação dos aspectos rurais sobre as bordas da cidade. Essa particularidade evidenciada na configuração da cidade média só é possível pelo fato do estreitamento das relações que a cidade média vivencia, ou seja, sua proximidade e interação com o mundo rural e outras cidades pequenas, que explanam suas ruralidades.

Desse modo, podemos inferir aqui as interações entre as cidades pequenas e médias, conferem a elas, formas socioespaciais definidas por esse contato. Levando em consideração também, que a própria cidade média interage com ela mesma, transformando e recriando suas relações internas pautadas pela aproximação do campo e cidade.

\title{
CONSIDERAÇÕES FINAIS
}

Este estudo buscou evidenciar algumas particularidades na produção e configuração socioespacial das cidades médias através das interações espaciais. Para isso, fizemos uma releitura do termo e sua concepção no meio geográfico em seus vários momentos históricos, chegando até sua atual delimitação.

Concluímos que a atual conjuntura global, que tendência uma ampliação das áreas em detrimento da reprodução do capital, atrelada ao desenvolvimento dos meios de comunicação e as condições viárias 
que conectam os lugares, acabam por fortalecer a articulação das redes geográficas formadas por cidades pequenas e médias. Sendo esta última, centralizadora pela sua complexidade funcional, polarizando as demais. Portanto, devido a essas interações entre os lugares diversos da rede, e principalmente pelo estreitamento das relações com as cidades pequenas, os fluxos de pessoas que transitam pela rede, seja pela utilização de serviços ou pela mão de obra em movimento, acabam por deixarem marcas impressas nas cidades. Pois, se fundem aspectos de comunidades rurais e urbanas.

A proximidade da periferia da cidade média com o mundo rural dinamiza o processo de interações entre esses espaços e cria condições únicas, como por exemplo, a vivência compartilhada de pessoas entre esses dois espaços, o rural e o urbano. Dada por uma exclusão do homem do campo pelo processo de avanço tecnológico e concentração fundiária, fazendo-o buscar na cidade meio de sobrevivência.

E a contraponto, vê-se também a incorporação das práticas do campo na vida cotidiana do homem da cidade, como na agricultura urbana. Prática encontrada nas periferias das cidades médias. Essa adaptação de atividades que em essência provém do campo e adentra sobre a forma e configuração do intraurbano da cidade média pode ser explicada também através das interações espaciais que se realizam na própria rede geográfica. De modo a abrir caminho para a circulação não somente entre lugares distintos, mas também para que as proximidades manifestem suas características por essa relação, como no caso da periferia que encontra nas bordas da cidade um mundo rural.

Portanto, podemos dizer que as interações espaciais podem ser analisadas em diferentes escalas com diferentes intensidades, promovendo, fundindo e transformando seus elementos. Trazendo para dentro do urbano da cidade média essas relações que são produto de um processo contraditório.

\section{REFERÊNCIAS}

AMORIM FILHO, O. B.; SENA FILHO, N. A Morfologia das Cidades Médias. Minas Gerais: Ed. Vieira, 2007.

CARNEIRO, M. J. Ruralidade: novas identidades em construção. Estudos Sociedade e Agricultura, Rio de Janeiro, n. 11, p. 53-75, out. 1998 . 
CATÃO, R. C.; REOLON, C. A.; MIYAZAKI, V. K. Interações Espaciais: Uma reflexão temática. Caminhos de Geografia, Uberlandia, v. 11, n. 35, p. 231-239, Set. 2010.

CORRÊA, R. L. Interações Espaciais. In. CASTRO, I. E.; GOMES, P. C.; CORRÊA, R. L. (Org.). Explorações Geográficas. 3 ed. Rio de Janeiro: Bertrand Brasil, 1997. p. 279-318.

CORRÊAA, R. L. Estudos Sobre a Rede Urbana. Rio de Janeiro: Bertrand Brasil, 2004.

CORRÊAA, R. L. Trajetórias geográficas. 3. Ed. Rio de Janeiro: Bertrand, 2005.

CORRÊA, R. L. Construindo o conceito de cidade média. In: SPOSITO, M. E.B. (Org.). Cidades Médias: espaços em transição. São Paulo: Expressão Popular, 2007.

GREGORY, D. et al. The Dictionary of Human Geography. 5th ed. Malden, USA: Willey BlackWell, 2005.

HARTSHORNE, R. Propósitos e Natureza da Geografia. São Paulo: Edusp, 1978.

INSTITUTO BRASILEIRO DE GEOGRAFIA E ESTATÍSTICA (IBGE). Disponível em: http://www.sidra.ibge.gov.br. Acesso em: 03 de agosto de 2014.

SAMPAIO, A. V. O.; GUSMÃO, A. D. F. Mobilidade do Trabalho e Produção do Espaço nas Cidades Médias. In: XVI Encontro Nacional de Geógrafos. Anais... Porto Alegre, 2010.

SAnTos, M. O Espaço Dividido: Os Dois Circuitos da Economia Urbana dos Países Subdesenvolvidos. São Paulo: Editora da Universidade de São Paulo, 2008. 